\title{
Fracture of the greater trochanter during hip replacement a retrospective analysis of $29 / 688$ cases
}

\begin{abstract}
Background and purpose: An unusual complication of total hip arthroplasty is fracture of the greater trochanter that occurs either intra-operatively or during the early post-op period. This study aims to define the incidence and consequences of this complication.

Methods: We reviewed retrospectively 688 total hip replacements operated on using a lateral approach with the patient in a supine position (Group A, $\mathrm{n}=372$ ) or lateral decubitus position (Group B, $\mathrm{n}=316$ ).

Results: 28 (21 in group A) iatrogenic fractures of the greater trochanter were identified, all except one in women. 15 (all from Group A) cases were diagnosed during the operation and were treated with wire fixation. The rest were diagnosed on radiographs during the first 3 months following the operation. 2 of these 13 cases presented with prosthesis dislocation. Acute post-op infection occurred in one patient (Group B) displaced nonunion occurred in 3 cases ( 2 group $A)$. Nonunion incidence was similar in both groups $\left(X^{2}\right.$ test, $\left.p=0.81\right)$, the rest of the fractures united with no displacement $(n=15)$ or minimal displacement $(n=12)$. The incidence of peri-operative trochanteric fracture was significantly lower in patients operated in the lateral decubitus position (X2 statistic, $\mathrm{p}<0.001)$.

Interpretation: The current results support the use of the lateral decubitus position as compared with the supine position during total hip arthroplasty via the Hardinge approach to prevent trochanteric fracture. This complication appears to be particularly common in elderly females perhaps due to bone frailty and osteoporosis.
\end{abstract}

Volume 8 Issue 5 - 2017

\author{
Mustafa Yassin, Mohammed Eisa, Avraham \\ Garti, Moshe Weisbort, Dror Robinson \\ Department of Orthopaedics, Hasharon Hospital, Tel Aviv \\ University, Israel
}

Correspondence: Dror Robinson, MD, Head Unit of Orthopedic Research, and Foot and Ankle Service, Hasharon Hospital, Rabin Medical Center, Petah Tikva, Israel, Tel 97239372233 Email dror61@protongmail.com

Received: July 15, 2017| Published: August 16, 2017

\section{Introduction}

Nonunion of the greater trochanter occasionally occurs following trochanteric osteotomy. ${ }^{1}$ without major consequences. The information regarding the incidence and the consequences of unintended trochanteric fracture is limited. Specifically, it is not clear whether trochanteric non-union or long term trochanteric pain is consequences of such fractures. Trochanteric nonunion may also increase the risk of prosthesis dislocation. ${ }^{2}$ Fracture of the greater trochanter rarely occurs after THR surgery without osteotomy. ${ }^{3}$ In the current comparative study, the incidence and clinical relevance of iatrogenic greater trochanter fractures in connection with the lateral Hardinge approach. ${ }^{4}$ were analyzed depending on the patient's position during the surgery in order to define whether the incidence varies depending on patient positioning.

\section{Patients and methods}

Between 1993 and 1999, 372 total hip replacements were performed in our department, all using Hardinge's (1982) lateral approach, with the patient in a supine position. ${ }^{5}$ These previously published results (Group A) were compared with those of a cohort of 316 patients operated on between 2005 and 2015 using the same surgical approach while the patient is in lateral decubitus position (Group B). Patient demographics are presented in Table 1 . All patients were operated by the authors, though surgical teams varied. Data collection was based on medical records and radiographs. The study was approved by the appropriate institutional research ethics committee and has been performed in accordance with the ethical standards as laid down in the 1964 Declaration of Helsinki and its later amendments.

The breakdown of the arthroplasty indications are delineated in Table 1. In group A there were 317 THRs due to arthrosis. Specifically for osteoarthrosis in 285 hips, rheumatoid arthritis in 12 hips, congenital dysplasia in 20 hips. In Group B 270 THRs were performed for osteoarthritis and the rest for rheumatoid and inflammatory arthritides. Seven cases in Group A were performed for post traumatic arthrosis secondary to acetabular fractures, in group B there were no such cases. In both groups the proportion of revision cases due to hemiarthroplasty conversion to primary procedure was similar (Table 1).

In group A there were 26 bilateral cases ( 24 osteoarthrosis and 2 rheumatoid arthritis) versus 17 such cases in Group B.

Group A had proportionally more cemented stems than in Group B that was operated on during subsequent decades.

\section{Results}

Iatrogenic fracture of the greater trochanter was identified in 29 hips-i.e., 27 in primary operations and 2 in a conversion of hemiarthroplasty to total hip replacement (overall greater trochanter fracture incidence was $4.2 \%$ ). 28 of the fractures occurred in women aged 68 (59-75) years $(6.9 \%)$, none of whom had received steroid treatment, a single case was identified in a 65 years old male undergoing arthroplasty due to osteoarthritis $(0.35 \%)$. In 21 cases $(4.1 \%)$, a cemented prosthesis had been used, in 8 cases $(4.5 \%)$ an uncemented prosthesis.

15 fractures were diagnosed during the operation and were treated by wire fixation. They all healed, 1 with minimal displacement. 12 fractures were diagnosed on the postoperative radiographs, all were minimally displaced (Table 2). They were treated with bed rest for 2 weeks followed by mobilization. In 2 hips, the fracture was not diagnosed on the post-op radiograph. Postoperative radiographs showed no fracture but the 2 late-diagnosed cases presented with hip dislocation, 1 in an uncemented prosthesis after 6 weeks and 1 in a 
cemented conversion of hemiarthroplasty to total hip replacement after 2 months. All the other fractures which had not been fixed healed with minimal displacement. In the 2 cases which presented with hip dislocation, the fracture displaced about $2 \mathrm{~cm}$ superiorly and did not unite. Both patients had some pain over the lateral upper thigh and their treatment consisted of long walks using two canes.

Table I Demographics of patients with peri-operative trochanteric fracture

\begin{tabular}{llll}
\hline Parameter & Group A & Group B & Significance \\
\hline Number of Subjects & 372 & 316 & $\mathrm{X}^{2}$ statistic \\
Female/Male & $210 / 136(56 \% / 44 \%)$ & $\begin{array}{l}192 / 124 \\
(60.7 \% / 39.3 \%)\end{array}$ & $\mathrm{P}=0.25$ \\
Age (Average \pm SD) & $72 \pm 9$ & $69 \pm 14$ & Student's t-test, $\mathrm{P}=0.048,95 \% \mathrm{Cl}=0-3.7$ \\
(Range) & $(45-8 \mathrm{I})$ & $(19-93)$ & $\mathrm{X}^{2}$ statistic \\
Procedure & Primary 349 & Primary Procedure 304 & $\mathrm{P}=0.16$ \\
& Conversion 23 & Conversion I2 & $\mathrm{X}^{2}$ statistic \\
Indication for Primary Procedure & Osteoarthritis 3I7 & Osteoarthritis 29I & $\mathrm{P}=0.0 \mathrm{I} 2$ \\
& AVN 25 & AVN I3 & $\mathrm{X}^{2}$ statistic \\
Fixation Technique & Post-Traumatic 7 & Post-Traumatic 0 & $\mathrm{P}<0.00 \mathrm{I}$ \\
\hline
\end{tabular}

Table 2 Greater Trochanter Fractures in Hip Total Arthroplasty

\begin{tabular}{|c|c|c|c|}
\hline Parameter & Group A & Group B & Statistical Significance \\
\hline Incidence & $\begin{array}{l}21 / 372 \\
-5.6 \%\end{array}$ & $\begin{array}{l}8 / 316 \\
-2.5 \%\end{array}$ & $\begin{array}{l}\mathrm{X}^{2} \text { statistic } \\
\mathrm{p}=0.043\end{array}$ \\
\hline Gender-specific Incidence & $\begin{array}{l}\text { Fx in } q \\
21 / 210(10 \%) \\
\text { Fx in } 0 \\
0 / 162(0 \%)\end{array}$ & $\begin{array}{l}\text { Fx in }+ \\
7 / 192(3.6 \%) \\
\text { Fx in } \\
\mathrm{I} / 124(0.8 \%)\end{array}$ & $\begin{array}{l}\mathrm{X}^{2} \text { statistic } \\
\mathrm{P}<0.00 \text { I }\end{array}$ \\
\hline Time of Fx Dx & & & \multirow[b]{2}{*}{$\begin{array}{l}X^{2} \text { statistic } \\
P<0.00 \text { I }\end{array}$} \\
\hline $\begin{array}{l}\text { Intra-op Diagnosis of Fx } \\
\text { Post-Op } \\
\text { First Follow-up }\end{array}$ & $\begin{array}{l}\text { I5/2I } \\
21-A p r \\
21-F e b\end{array}$ & $\begin{array}{l}0 / 8 \\
8-A u g \\
0 / 8\end{array}$ & \\
\hline LAF Status & & & \\
\hline $\begin{array}{l}\text { Asymptomatic } \\
\text { Pain } \\
\text { Limp \& Pain }\end{array}$ & $\begin{array}{l}2 \text { I-Jul } \\
21 \text {-Jun } \\
2 \text { I-Aug }\end{array}$ & $\begin{array}{l}\text { 8-Jul } \\
8 \text {-Jan } \\
0 / 8\end{array}$ & $\begin{array}{l}X^{2} \text { statistic } \\
P=0.028\end{array}$ \\
\hline
\end{tabular}

Dx: Diagnosis; Fx: Fracture; LFU: Last Available Follow-up

Overall, of the 29 cases, 8 patients had a painful limp at followup, 2 of them also complained of pain over the trochanteric region, 7 had pain without limp. The pain was located over the greater trochanter region. 14 were asymptomatic. The prevalence of pain and limp was higher in the group operated supine than those operated in lateral decubitus position. The fractures in the lateral decubitus group were not diagnosed intra-operatively and thus were not fixed. This difference might account for the lesser long-term complaints in Group $\mathrm{B}$ as some of the complaints might be caused by soft tissue irritation by the wires.

\section{Discussion}

The Hardinge approach is one of the more popular ones for total hip arthroplasty. ${ }^{6}$ Damage to the abductor mechanism leads to limp in about 5 percent of cases, which is the principal draw-back of the lateral approach. ${ }^{7}$ In a series of 688 total hip arthroplasties using a lateral Hardinge approach, 29 trochanteric fractures occurred, nearly all in post-menopausal women.

During the Hardinge approach, two likely timepoints of trochanteric fracture occur. The first is during femoral preparation in the adducted and externally rotated position as tensile stress is applied by the gluteus medius and short external rotators. This maneuver is especially stressful on the trochanter in overweight patients. The other timepoint when fracture might occur, is when a sub-acetabular retractor pushes the gluteal muscles. The stem type is related to the frequency of greater trochanteric fracture. Most cementless stems are bulkier than their cemented counterparts and could have been assumed to be associated with greater trochanter fractures. The observed incidence is different. The fractures incidence is higher in cemented stems $(6.3 \%$ in Group A vs. $4.1 \%$ in Group B) than in uncemented stems (1.8 Group A vs. $0 \%$ in Group B). The reduction in fracture rate in uncemented stems is probably due to the greater age of the patients receiving cemented stems.

While the operative maneuvers are similar in both patient positions, the lateral decubitus positioning is associated with a significantly lower GT fracture rate (X2 statistic, $p=0.022)$ regardless of the stem fixation technique. In Group B we had more uncemented stems, but the decrease in the rate of GT fractures remained statistically significant.

To prevent the risk of iatrogenic fracture of the greater trochanter during the operation, care should be taken to release the scarred tissue and the muscles around the femoral neck and trochanteric region, especially in osteoporotic and overweight patients. This will permit easy external rotation and adduction of the femur. Lateral decubitus patient positioning is apparently helpful, specifically in obese individuals, as the excess fat tissue has more space to shift downward, making the femoral rotation maneuver less stressful. Apparently, the lateral decubitus position facilitates this soft tissue release maneuver thus lowering the fracture rate. 
The GT fractures diagnosed following the first post-op radiographs might either be stress fractures or un-displaced fractures that could not be identified on the post-op radiograph. The lack of severe postop pain might indicate that the option of a stress fracture is more plausible.

All 15 fractures found and fixed during the operation healed without complications. A displaced fracture diagnosed after the procedure might lead to dislocation and should be fixed as soon as diagnosed. The long term consequence of the trochanteric fractures is limited. The principal consequence appears to be slight limping which was noted in 8 patients. Patients who underwent internal fixation during surgery tended to have some local pain as well.

We conclude that a trochanteric fracture after the lateral Hardinge approach has a minor effect on the overall outcome. The incidence of trochanteric fracture is significantly higher in female patients. Such patients should probably be operated solely in the lateral decubitus position.

\section{Acknowledgements}

None.

\section{Conflicts of Interest}

On behalf of all authors, the corresponding author states that there is no conflict of interest.

\section{References}

1. Amstutz HC, Maki S Complications of trochanteric osteotomy in total hip replacement. J Bone Joint Surg Am. 1978;60(2):214-216.

2. Woo RY, Morrey BF Dislocations after total hip arthroplasty. $J$ Bone Joint Surg Am. 1982;64(9):1295-1306.

3. Probst A, Wetterkamp D, Neuber M Iatrogenic avulsion of the greater trochanter during prosthetic replacement of the hip. Unfallchirurg. 1999;102(6):497-499.

4. Connault P, Gayet LE, Merienne JF et al. Total arthroplasty, using Hardinge's approach, combined with trochanterotomy: comparative results of 200 cases. Rev Chir Orthop Reparatrice Appar Mot. 1995;81(1):44-50.

5. Hendel D, Yasin M, Garti A et al. Fracture of the greater trochanter during hip replacement: a retrospective analysis of 21/372 cases. Acta Orthop Scand. 2002;73(3):295-297.

6. Kelmanovich D, Parks ML, Sinha R et al. Surgical approaches to total hip arthroplasty. J South Orthop Assoc. 2003;12(2):90-94.

7. Berstock JR, Blom AW, Beswick AD A systematic review and meta-analysis of complications following the posterior and lateral surgical approaches to total hip arthroplasty. Ann R Coll Surg Engl. 2015;97(1):11-16. 